\title{
A Facile Design of Colourimetric Polyurethane Nanofibrous Sensor Containing Natural Indicator Dye for Detecting Ammonia Vapour
}

\author{
Ayben Pakolpakçıl *(D) and Zbigniew Draczyński (D) \\ Institute of Materials Science of Textiles and Polymer Composites, Lodz University of Technology, \\ 116 Żeromskiego Street, 90-924 Lodz, Poland; zbigniew.draczynski@p.lodz.pl \\ * Correspondence: ayben_p@yahoo.com
}

check for

updates

Citation: Pakolpakçıl, A.; Draczyński, Z. A Facile Design of Colourimetric Polyurethane Nanofibrous Sensor Containing Natural Indicator Dye for Detecting Ammonia Vapour. Materials 2021, 14 , 6949. https://doi.org/10.3390/ ma14226949

Academic Editors: Andrea Ehrmann and Francisco Javier Espinach Orús

Received: 23 September 2021

Accepted: 15 November 2021

Published: 17 November 2021

Publisher's Note: MDPI stays neutral with regard to jurisdictional claims in published maps and institutional affiliations.

Copyright: (C) 2021 by the authors. Licensee MDPI, Basel, Switzerland. This article is an open access article distributed under the terms and conditions of the Creative Commons Attribution (CC BY) license (https:/ / creativecommons.org/licenses/by/ $4.0 /)$.

\begin{abstract}
Chemicals and industrial gases endanger both human health and the environment. The inhalation of colourless ammonia gas $\left(\mathrm{NH}_{3}\right)$ can cause organ damage or even death in humans. Colourimetric materials are becoming more popular in the search for smart textiles for both fashion and specific occupational applications. Colourimetric textile sensors based on indicator dyes could be very useful for detecting strong gaseous conditions and monitoring gas leaks. In this study, black carrot extract (BCE) as a natural indicator dye and polyurethane (PU) polymer were used to develop a colourimetric sensor by electrospinning. The properties of the BCE/PU nanofibrous mats were characterized by the Fourier transform infrared spectrum (FTIR) and a scanning electron microscope (SEM). The BCE caused a change in the morphology of the PU nanofibrous mat. To evaluate the colour shift due to $\mathrm{NH}_{3}$ vapour, the $\mathrm{BCE} / \mathrm{PU}$ nanofibrous mats were photographed by a camera, and software was used to obtain the quantitative colour data (CIE L*a*b). The BCE/PU nanofibrous exhibited a remarkable colour change from pink-red to green-blue under $\mathrm{NH}_{3}$ vapour conditions with a fast response time ( $\leq 30 \mathrm{~s})$. These findings showed that colourimetric nanofibrous textile sensors could be a promising in situ material in protective clothing that changes colour when exposed to harmful gases.
\end{abstract}

Keywords: gas detection; natural indicator dyes; protective textiles; sensor; nanofibre; electrospinning

\section{Introduction}

Colour is a powerful communication tool and can be used to signal action. Colourimetric markers have received a great deal of attention in the last decade. They can provide useful information with visible colour changes as a signal in a variety of applications today, from biomedical to safety equipment, where they detect and alert us to changes in the environment [1,2]. According to the Allied Market Research Inc. (Portland, OR, USA) report, the sensor market size was estimated at USD 166.69 billion in 2019 and is expected to reach USD 345.77 billion by 2028 [3]. Colourimetric sensors have attracted the interest of researchers due to their ease of preparation, naked-eye sensing, quick detection, and high sensitivity in response to the growing demand for in-situ analysis [4].

Ammonia $\left(\mathrm{NH}_{3}\right)$ is used in a variety of sectors, including industrial cleaning, chemical production, and food production. Despite its usefulness, it is a hazardous chemical that can cause irritation and burns when inhaled or when it comes into contact with the skin or eyes. $\mathrm{NH}_{3}$ gas is difficult to detect with the naked eye because it is colourless and spreads quickly. As a result, in industries that store, handle, or manufacture dangerous substances, continual monitoring is required to identify gas leaks. This situation necessitates study into detecting ammonia gas using a simple approach in everyday situations. Electrochemical, catalytic combustion, semiconductor, and infrared gas sensors are commonly used in numerous industries to detect gas leakage. The demand for portable gas sensors is increasing, and these sensors are being downsized, but their limited portability, issues with lowering 
power consumption, and high production costs continue to be impediments. Sensors directly applied to textiles are frequently investigated to solve these challenges, with electro-resistive sensors accounting for the majority of these investigations. However, they require a power supply, making them difficult to include in protective clothing [5-9].

It becomes necessary to monitor environmental contaminants accurately, cheaply, and on-site. The use of visual indicators is one of the ways of detecting ammonia gas. The incorporation of these devices as colourimetric gas sensors into textiles is an innovative and intriguing application, and they are part of a new generation of smart textiles for monitoring various volatile chemicals in the environment. Textile materials have numerous advantages, such as flexibility, strength, and lightness, and they can be a good way to develop a colourimetric sensing material for gas leakage monitoring in this context [4,7-9].

Detection capability, selectivity, sensitivity, and response time properties are important parameters to produce a colourimetric sensor. Improving the sensing ability of the sensor by increasing its surface area is a way to improve these sensors [10]. The nanofibres have many advanced properties, such as tunable porosity, a high specific surface area to volume ratio, and flexibility of surface functionalization, making them promising candidates for substrates to enhance the performance of the sensors. Electrospinning is a method of producing nanomaterials that use electric force to form continuous fibres with diameters ranging from nanometres to micrometres. In the electrospinning process, a polymer solution is enclosed in a syringe with a linked power source. A high-voltage power source is used to charge the polymer solution. This droplet is drawn into a Taylor cone by the electric field. Polymer droplets break apart and a steady jet forms when the viscosity and surface tension of the solution are suitable [11-15].

Some researchers have focused on the detection performance of the produced sensors in the presence of liquid or gaseous alkalis and acids [16-22]. Eco-friendly processes and production costs should be considered for commercial textile sensor applications [23,24]. Electrospinning technology has a number of advantages, including ease of use, environmentally friendly processes, and a low cost [25-30] for developing textile-based colourchange sensors.

Natural dyes are in high demand for $\mathrm{pH}$-sensitive indicator manufacturing due to their non-toxic and environmentally friendly properties. Anthocyanins are a halochromic class of natural pigments that can generate a variety of colours, including reddish-pink in acidic environments, bluish-purple in neutral mediums, and greenish-yellow in alkaline conditions. Colour changes in these dyes occur because of the phenolic substances-for example, cyanidin, delphinidin, pelargonidin, peonidin, and petunidin-which are exposed to auxiliary changes with a variety in $\mathrm{pH}[31,32]$. Black carrots (Daucus carota sativus var. atrorubens) are native to Turkey and the Middle and Far East and have been grown for at least 3000 years. They have been successfully used to colour food industry material due to their high heat, light, and $\mathrm{pH}$ stability. In addition, they are plentiful and cheap [33-35], which is an advantage in terms of low production costs for the development of atextile-based colourimetric sensor. Several studies have been carried out using anthocyanin extracts from black carrot as a colour-changing nanofibrous sensor. The electrospun polyvinyl alcohol film with anthocyanins from black carrot was developed by Goksen and Ekiz [36]. Moradi et al. [37] investigated the use of an intelligent $\mathrm{pH}$-sensing indicator based on bacterial nanocellulose and black carrot anthocyanins to monitor the freshness of rainbow trout and common carp fillets during storage. Goodarzi et al. [38] developed an intelligent freshness indicator by immobilizing anthocyanins of black carrot within a starch matrix to monitor milk spoilage. Pakolpakçl et al. [39] blended black carrot extract with polyvinyl alcohol and sodium alginate to develop $\mathrm{pH}$-sensing nanofibrous mats for wound dressing.

Polyurethane (PU) is an important polymer that is widely used in various fields including automotive, furniture, construction, clothing, and footwear industries. PU is widely used for its low cost, chemical resistance, tear resistance, abrasive resistance, and high load-bearing properties [40,41]. Electrospun PU textiles have been used as filters [42], 
wound dressings [43], protective clothing [44], packaging [45], and wearable sensors [46]. Developing a colourimetric sensor that utilizes a mixture of black carrot extract and PU might be an option in a gas sensor for protective clothing. There is no previous research based on black carrot extract (BCE) and $\mathrm{PU}$ as a colourimetric nanofibrous sensor for $\mathrm{NH}_{3}$ vapour in the literature. The electrospinning process was used in this study to produce black carrot extract-loaded PU nanofibrous mats (Figure 1). The electrospun mats' morphology, chemical composition, and colour change behaviour were investigated. The UV-Vis spectra of $\mathrm{BCE}$ solutions in different $\mathrm{pH}$ values $(\mathrm{pH} 2-12)$ were determined by measuring their absorbance at the maximum wavelength in the visible range. According to the findings, the BCE-loaded PU nanofibrous mat can be considered as an NH3 detector which is critical for human health protection. In practice, the BCE/PU nanofibrous sensor does not require any complicated instruments, electronic components, or even skilled personnel.

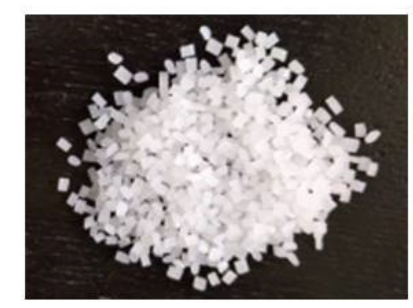

Thermoplastic polyurethane

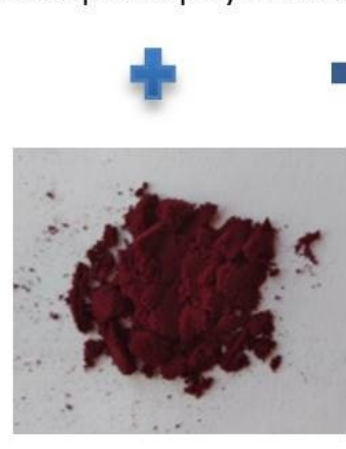

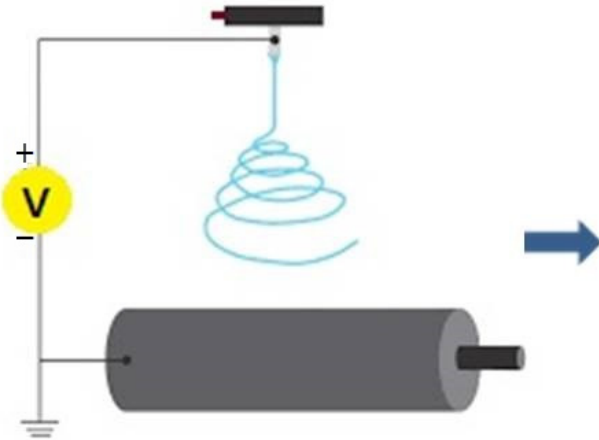

Electrospinning

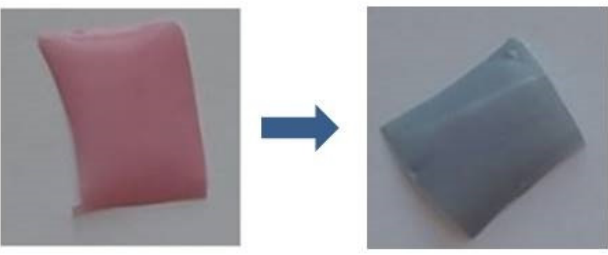

Nanofibrous mat Expose to ammonia vapor

Black carrot extract

Figure 1. The facile method and experimental study of developing a colourimetric polyurethane nanofibrous sensor containing natural indicator dye for detecting ammonia vapour.

\section{Materials and Methods}

\subsection{Materials}

The PU polymer was supplied from BASF (BASF GmbH, Lemförde, Germany) and used in the production of the commercial product (Elastollan ${ }^{\circledR} \mathrm{C} 95, \mathrm{BASF} \mathrm{GmbH}$, Lemförde, Germany) is a polyester-based PU) nanofibrous mat. The BCE was acquired from Pak Natural (Global Inovatif, İstanbul, Turkey). Acetic acid, ammonia (25\%), dimethylformamide ( $98 \%$ ), sodium acetate trihydrate, sodium dihydrogen phosphate dihydrate, and sodium hydrogen phosphate dihydrate were purchased from Merck (MERCK SP. Z O.O., Warsaw, Poland). All chemicals were used as received, with no further purification. The experimental investigation was conducted with deionized water (DE 20 Plus-Polna, Przemysl, Poland).

\subsection{Preparation of the Electrospun Nanofibrous Mats}

PU polymer was dissolved in dimethylformamide after $24 \mathrm{~h}$ of mixing on a magnetic stirrer (Magnetic motor stirrer MS 11, WIGO, Warsaw, Poland) at a concentration of 13\% $(w / v)$. Following that, two concentrations of black carrot extract $(0.25 \%$ and $0.5 \mathrm{wt} . \%)$ were added to the PU polymer solution. After that, the BCE/PU mixtures were prepared by 
stirring for $2 \mathrm{~h}$ at a $500 \mathrm{rpm}$ stirring rate. The whole solutions preparation process was performed at room temperature $\left((25 \pm 2){ }^{\circ} \mathrm{C}\right)$.

The prepared solutions were placed in a $20 \mathrm{~mL}$ syringe with a $0.8 \mathrm{~mm}$ inner diameter stainless-steel needle (KDM ${ }^{\circledR}$ KD Medical GmbH, Berlin, Germany). The electrospun mats were produced using a home-made electrospinning machine (Lodz University of Technology, Lodz, Poland). A drum collector covered with aluminium was used to collect electrospun mats. The flow rate and applied voltages were $0.5 \mathrm{~mL} / \mathrm{h}$ and $35 \mathrm{kV}$, respectively, during electrospinning, with a distance of $30 \mathrm{~cm}$ between the tip of the syringe and the surface of the static collector and a drum speed of $30 \mathrm{rpm}$. The experimental study was performed in room conditions (relative humidity $=(50 \pm 5) \%$; temperature $=(25 \pm 2)^{\circ} \mathrm{C}$ ). The samples produced were kept in a box at $-20^{\circ} \mathrm{C}$ for further investigations.

\subsection{Characterization of the Electrospun Nanofibrous Mats}

The morphology of the electrospun PU and BCE/PU nanofibrous mats was analyzed by scanning electron microscopy (SEM) (Nova ${ }^{\mathrm{TM}}$ NanoSEM 230, FEI Company, Hillsboro, OR, USA). Surface morphologies were imaged at a magnification of 10,000. The diameter distribution and average diameters of the fibres were calculated from the pictures using software (Image J, National Institutes of Health, Madison, WI, USA) with at least 100 measurements per sample.

A Nicolet 6700 spectrometer (Thermo Scientific, Madison, WI, USA) was used to measure the attenuated total reflectance-Fourier transform infrared spectroscopy (ATRFTIR) of samples. All spectra were recorded within a range of $600-4000 \mathrm{~cm}^{-1}$. The OMNIC Specta Software (Thermo Scientific, Madison, WI, USA) was used to further analyse the spectra.

A digital thickness gauge for nonwovens (Checkline J-40-V, Electromatic Equipment Co New York, NY, USA) was used to measure the thickness of the electrospun mats at 5 points. The average and standard deviations of the obtained results were calculated. The test was performed in room conditions (relative humidity $=(50 \pm 5) \%$; temperature $=(25 \pm 2){ }^{\circ} \mathrm{C}$ ).

\subsection{UV-Vis Analysis}

Before starting the study, the colour-changing property of the purchased black carrot extract was examined. Colour measurements were performed to evaluate the colour properties of $\mathrm{BCE}$ at different $\mathrm{pH}$ values. For this purpose, $0.1 \mathrm{~g}$ BCE was dissolved in $100 \mathrm{~mL}$ deionized water, and BCE solution was prepared. Acetate buffers ( $\mathrm{pH} 2-4)$, phosphate buffers ( $\mathrm{pH} 6-9$ ), and ammonia buffers ( $\mathrm{pH}$ 10-12) were used to adjust the $\mathrm{pH}$ of the medium. Prepared buffer solutions were used in a volume ratio of 1:5 to dilute the BCE solutions. The absorbance of the prepared solutions was measured by UV-Vis spectrophotometer (Lambda 2, Perkin Elmer, MA, USA). In the wavelength range of 400 to $700 \mathrm{~nm}$, absorption spectra were obtained. For the investigation, the SpectraGryph program (v1.2.14, Oberstdorf, Germany) was utilized.

\subsection{Characterizations of the Colour Change Behaviour of Nanofibrous Mats}

The colour change behaviour of BCE-loaded nanofibrous in the presence of ammonia vapour was recorded by using a camera. For this purpose, an approximately $10 \mathrm{~mm} \times 10 \mathrm{~mm}$ mat was exposed for $30 \mathrm{~s}$ at a distance of around $1 \mathrm{~cm}$ above a flask previously filled with $10 \mathrm{~mL}$ ammonia solution $(25 \%)$, and the colour change of BCE-loaded nanofibrous was tracked. Then, the sample was removed from the vapour, and the colour recovered (reversibility) was recorded (Video S1). Photographs were produced from video. They were used for analysis and were taken under the same lighting conditions. The experimental study was performed in room conditions (relative humidity $=(50 \pm 5) \%$; temperature $\left.=(25 \pm 2)^{\circ} \mathrm{C}\right)$.

For colour analysis, $50 \times 50$ pixel samples with the same distance (on the ground) from the image were used. CIE L*a*b* values of the obtained photos were provided by using software (Adobe Photoshop CS5, Phoenix, AR, USA). In CIE L*a* $\mathrm{b}^{*}$ colour space 
values, $L^{*}$ indicates the level of lightness; $a^{*}$ represents the position between red and green, where a positive number indicates red and a negative number indicates green; $b^{*}$ represents the position between yellow and blue, where $a \mathrm{~b}$ positive number indicates yellow and $a b$ negative number indicates blue. The total colour differences were calculated by the following equation:

$$
\text { Total colour difference }\left(\Delta \mathrm{Eab}^{*}\right)=\left[\left(\Delta \mathrm{L}^{*}\right)^{2}+\left(\Delta \mathrm{a}^{*}\right)^{2}+\left(\Delta \mathrm{b}^{*}\right)^{2}\right]^{1 / 2}
$$

where $\Delta \mathrm{Eab}^{*}$ is the distance between the two colours in the CIE $\mathrm{L}^{*} \mathrm{a}^{*} \mathrm{~b}^{*}$ colour space, and $\Delta$ is the difference between the sample's numeric value and the standard's numeric value [47].

\section{Result and Discussion}

\subsection{Characterizations of the Nanofibrous Mats}

To evaluate the influence of electrospinning solution composition on the structure of the nanofibrous mat, different concentrations ( 0.25 and $0.5 \mathrm{wt} \%$ ) of BCE/PU solution were prepared and used in the fabrication of fibres in this study. The SEM images and the average diameter and fibre diameter distributions of the PU and BCE-loaded PU electrospun mats are given in Figure 2. The structure of electrospun PU nanofibrous was beadless, continuous, and homogeneous (Figure 2a). The average diameter of the electrospun PU nanofibre in this work was $329 \mathrm{~nm}$, which agrees with the findings of Nirmala et al. [48], who reported a similar average diameter for electrospun PU nanofibrous (200-500 nm). When comparing sample SEM images, the presence of BCE in the PU solution had an unfavourable impact on the morphology of mats. The structures of BCE/PU nanofibres were less regular with a few beads, according to SEM pictures of PU containing BCE nanofibres (Figure 2b,c). Agarwal et al. [49] have reported that after adding indicator dyes to Nylon 6 solution, commonly undesired fibre shapes (droplets) formed on electrospun nanoweb surfaces, which could be due to fibre instability or insoluble dyes. The average fibre diameter of BCE-loaded PU nanofibres was found to be in the range of $259-283 \mathrm{~nm}$. BCE includes anthocyanins, carbohydrates, minerals, and vitamins [33]. The presence of ions in solutions may explain the increased conductivity of electrospinning solutions causing the jet to stretch more, resulting in a thinner diameter of nanofibres. Pakolpakç1 et al. [39] have shown that the presence of black carrot extract in polyvinyl alcohol and sodium alginate mixture solution increased the conductivity of the electrospinning solution. In previous studies, at high voltage, solutions pass more quickly through the capillary because the greater electrostatic repulsive forces are exposed, which leads to a defective fibre structure [11-13,39,50]. The reason for the reduction in fibre diameter can be attributed to the fact that the BCE/PU solution may have higher conductivity than the PU solution. While the fibre diameter was $259 \mathrm{~nm}$ at the $0.25 \mathrm{wt} \%$ concentration, the fibre diameter was $283 \mathrm{~nm}$ at the $0.5 \mathrm{wt} \%$ concentration. As expected, increasing the dye concentration resulted in increased viscosity. The increased viscosity of solutions might be attributed to an increase in solution concentration as well as hydrogen bonding interactions between PU and black carrot extract. Therefore, a change in diameter was observed. While the PU exhibited a variation in the diameters of the nanofibres between 100 and $800 \mathrm{~nm}$, the 0.25-BCE/PU and 0.5-BCE/PU diameters ranged between 100 and $600 \mathrm{~nm}$ (Figure 2a-c). The morphologies of PU nanofibres containing different quantities of BCE indicated randomly oriented fibres with a defective structure. Increasing the concentration of $\mathrm{BCE}$ had no effect on the morphology of mats. The thicknesses of the PU, 0.25-BCE/PU, and 0.5-BCE/PU electrospun nonwoven fabrics were measured as $(64 \pm 8) \mu \mathrm{m},(71 \pm 2) \mu \mathrm{m}$, and $(65 \pm 3) \mu \mathrm{m}$, respectively. 

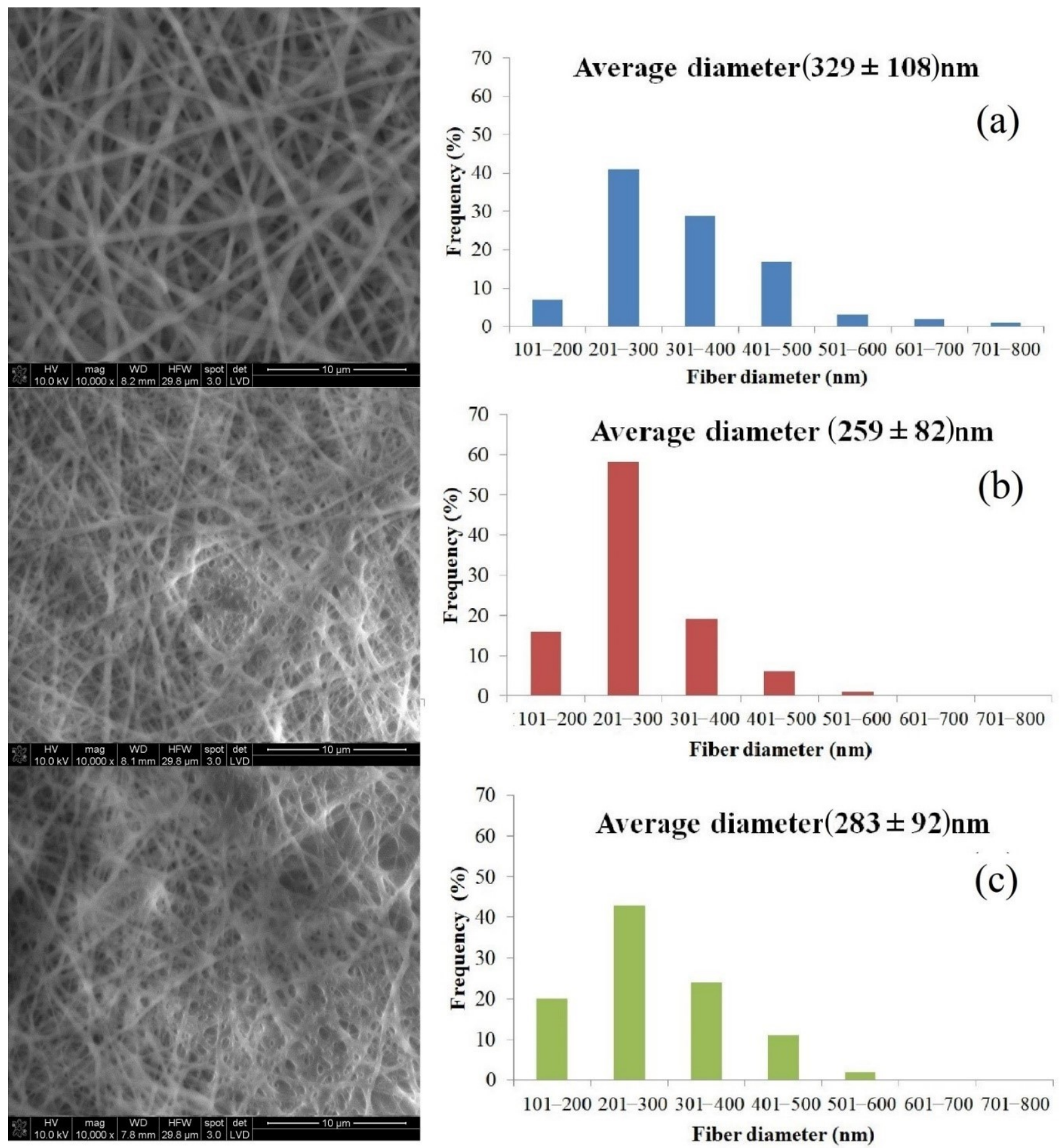

Figure 2. SEM morphology and diameter distribution of the PU and BCE/PU nanofibrous mats with BCE content (a) PU (b) $0.25-\mathrm{BCE} / \mathrm{PU}$ and (c) $0.5-\mathrm{BCE} / \mathrm{PU}$.

The functional groups of $\mathrm{BCE}, \mathrm{PU}$, and $\mathrm{BCE} / \mathrm{PU}$ nanofibrous mats can be seen in the spectra (Figure 3). The observed peaks in the FTIR spectra of the PU nanofibrous mat were assigned as $3304 \mathrm{~cm}^{-1}$ (N-H stretching), $2970 \mathrm{~cm}^{-1}\left(\mathrm{CH}_{2}\right.$ stretching), $1703 \mathrm{~cm}^{-1}$ ( $\mathrm{C}=\mathrm{O}$ stretching), and $1222 \mathrm{~cm}^{-1}$ (C-O stretching). The peaks are in agreement with the PU reports in the literature $[43,48]$. The observed peaks in the FTIR spectra of the BCE were assigned as $3300 \mathrm{~cm}^{-1}$ (OH groups), $2937 \mathrm{~cm}^{-1}$ (=C-H stretching), $1027 \mathrm{~cm}^{-1}$ (C-O stretching), and $923 \mathrm{~cm}^{-1}(=\mathrm{C}-\mathrm{H})$ [51]. Between the PU and the BCE/PU nanofibres, there were notable differences in peak intensities. With the addition of $\mathrm{BCE}$, the adsorption bands in the frequency range of $3600-3200 \mathrm{~cm}^{-1}$ were broadened due to the hydroxyl 
groups of the groups in BCE. Furthermore, depending on the BCE content, the strength of the absorption band caused by the stretching of $-\mathrm{OH}$ groups increased, suggesting that $\mathrm{BCE}$ hydroxyl groups were integrated into the PU nanofibrous mats. This result showed an interaction of the molecules in the functionalized nanofibres.

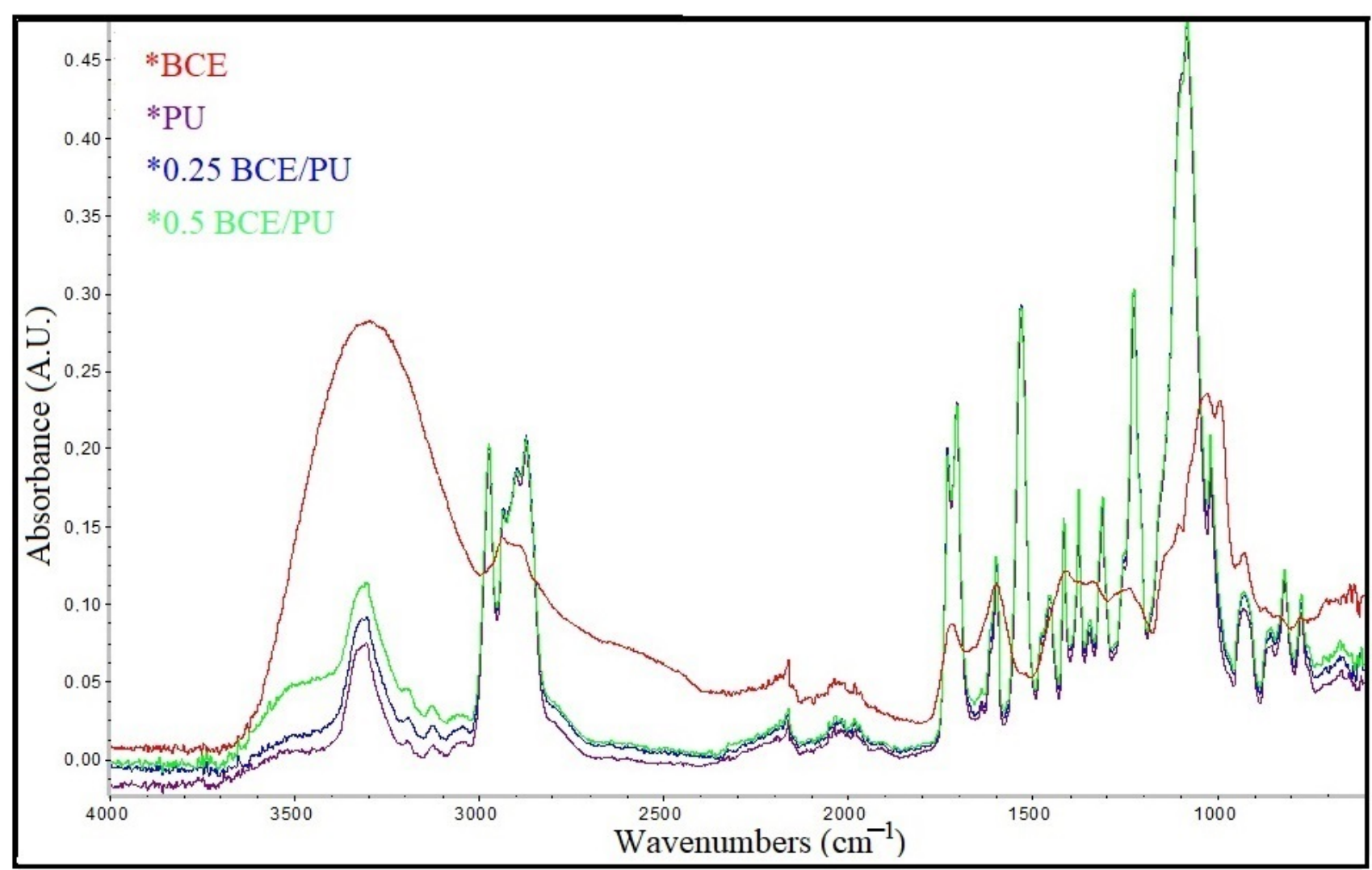

Figure 3. ATR-FTIR spectra of BCE, the electrospun PU, and BCE/PU nanofibrous.

\subsection{Results of UV-Vis Analysis}

The UV-Vis absorption spectra of the BCE solutions at different $\mathrm{pH}$ values are shown in Figure 4. A comparison with the literature indicates that the spectra are typical of anthocyanin pigments, with absorbances in the range of 450-600 $\mathrm{nm}$ [52]. The peaks in Figure 4 are in agreement with the UV-Vis absorption spectra of the BCE solutions in the literature [39]. As can be seen, UV absorption was measured at $524 \mathrm{~nm}$ and $525 \mathrm{~nm}$, respectively, for $\mathrm{pH} 2$ and 3 . The intensity of the peak decreased with increasing $\mathrm{pH}$. At $\mathrm{pH} 4-6$, clear absorbance peaks can be observed at 533 and $550 \mathrm{~nm}$. At $\mathrm{pH} 7$, the absorption band shifted to $553 \mathrm{~nm}$. When the $\mathrm{pH}$ was increased to 8 , the absorption band shifted to $595 \mathrm{~nm}$ along with a broad and increase in intensity. This behaviour was linked to the chemical structural change of black carrots under different $\mathrm{pH}$ conditions $[37,39]$. The maximum absorption peak of the solution was ascribed to flavylium cations at $524 \mathrm{~nm}$ ( $\mathrm{pH} 2)$, whereas the maximum adsorption peak dropped and moved to $553 \mathrm{~nm}(\mathrm{pH} 2-7)$, which corresponded to the production of quinonoid bases. At $\mathrm{pH}>7$, second deprotonation produced the carbinol pseudobase, causing the maximum adsorption peak to move to $595 \mathrm{~nm}$. From low to high $\mathrm{pH}$ values, a bathochromic change was visible. The colour change behaviour of the BCE solutions was demonstrated using a UV-Vis spectrum, which showed the changes within the medium and could be used to develop a colourimetric sensor. 


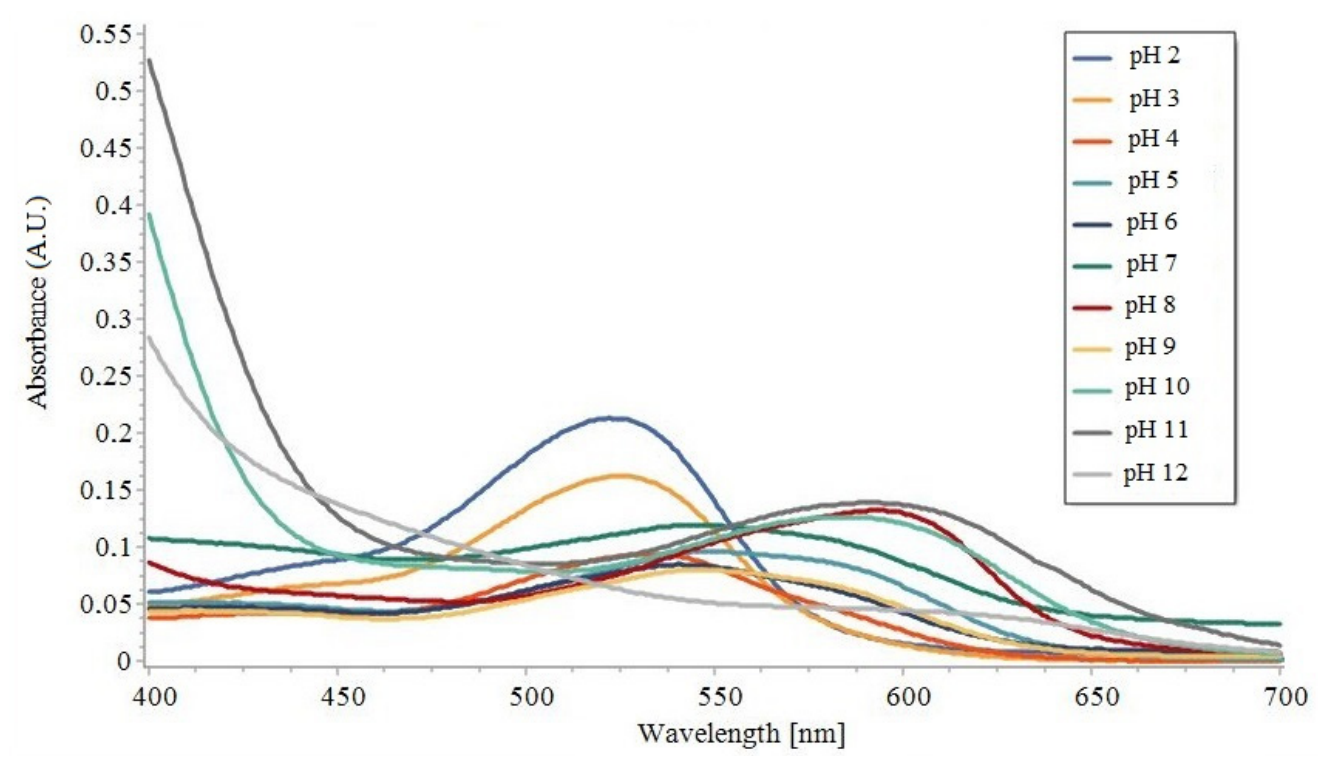

Figure 4. UV-Vis absorbance spectra of the BCE solutions at pH 2-12.

\subsection{Colour Change Behaviour of the Electrospun Mats}

In industrial operations or personal protective equipment and clothing, the ability to detect alkaline atmospheres quickly with a visual signal is quite useful. To test the $\mathrm{NH}_{3}$ sensing capacity, the BCE/PU nanofibrous mat was held in a medium with a certain volume of vigorous liquid ammonia from which $\mathrm{NH}_{3}$ may be easily volatilized. The colour change capability was verified and recorded by a camera after the $0.5-\mathrm{BCE} / \mathrm{PU}$ nanofibrous mats were exposed to $\mathrm{NH}_{3}$ vapour. The video of the colour change performance of the sample is presented in the Supplementary Materials (Video S1). As shown in Figure 5a, the nanofibrous mats were exposed to the $\mathrm{NH}_{3}$ vapour. After exposure, the colour of the mats changed. The $\mathrm{BCE} / \mathrm{PU}$ nanofibrous mats showed a fast response time $(\leq 30 \mathrm{~s})$. The presence of $\mathrm{NH}_{3}$ in the environment also provided an alkaline medium on the nanofibre surface. Anthocyanins can change colour depending on the $\mathrm{pH}$ of their surroundings. In acidic medium, they usually turn purple-red, while in basic medium, they turn green-blue [53]. The rapid colour conversion with $\mathrm{NH}_{3}$ vapour may be related to the large surface area and high porosity of the BCE/PU nanofibrous mats and the fast transformation of black carrot molecular structures. The BCE/PU nanofibrous mats exhibited a good colour change, and colour differences were easily discernible with the naked eye. Furthermore, the colour recovery (reversibility) of the functionalized nanofibres was tested for around $5 \mathrm{~min}$ as shown in Figure 5b. The nanofibrous mats became purple within a short time. Due to its different molecular structures, anthocyanin shows colour changes that depend on the variation of $\mathrm{pH}$. At lower $\mathrm{pH}$, the flavylium cation is prominent in anthocyanin structures, contributing to a red colour. Since the $\mathrm{pH}$ value is between 4 and 6 , the flavylium cation is equalized to the colourless open chalcone form and hydrated to give a colourless carbinol pseudobase. At this $\mathrm{pH}$ range, a blend of harmony types of anthocyanin might exist, including chalcone (yellow), carbinol pseudo base (dreary), quinonoidal base (purple or blue), and flavylium cation (red), and this causes anthocyanin to form a purple colour. At $\mathrm{pH} 6$ to 7 , the quinonoid bases may deprotonate, and this leads to a bluish quinonoid anhydro base. With further increases in $\mathrm{pH}$, the anthocyanins are corrupted dependent upon their substituent groups. This opens the central pyran ring with dominating anhydro bases, resulting in anthocyanin production of yellow carbinol [32,53-55]. 
(a)

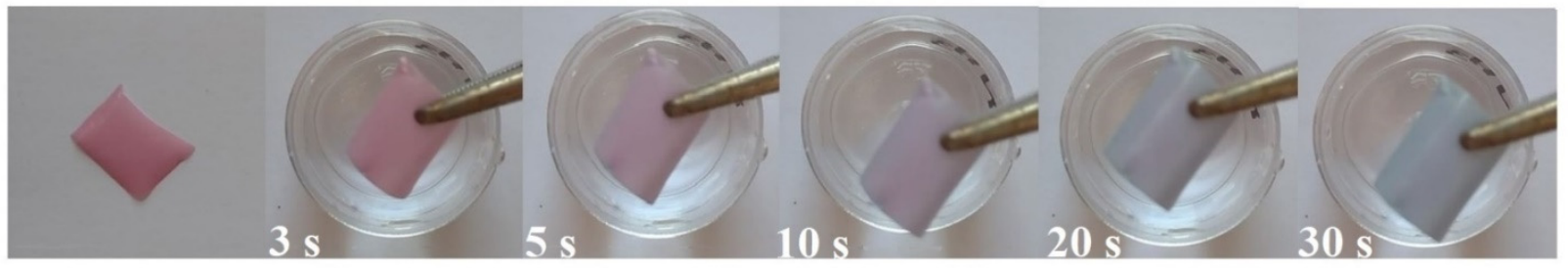

(b)

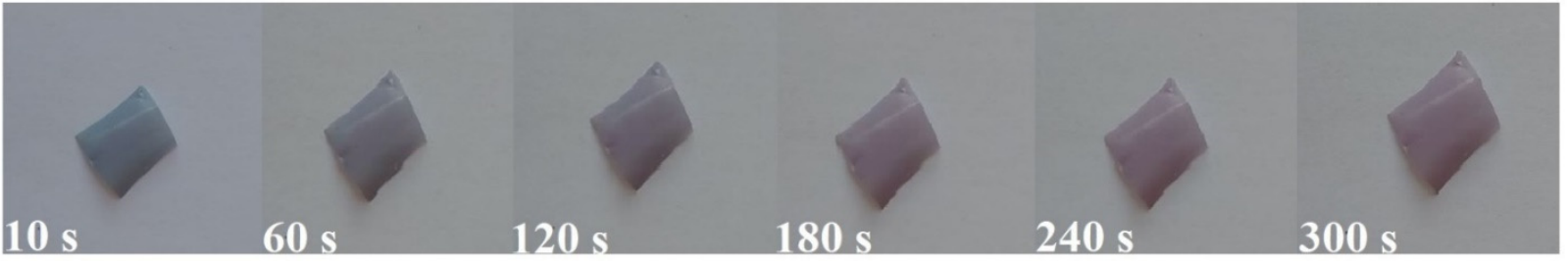

Figure 5. The colour changing performance of BCE-loaded PU nanofibrous mats after exposure (a) to ammonia vapour and subsequent removal (b).

The use of CIELab coordinates to determine colourimetric parameters has proven to be a simple and effective method of investigating a textile material's colourimetric activities. The appearance of a colour in CIELab coordinates provides an objective measurement of the visual perception of that colour. The specification of colour in CIELab values also allows for the evaluation of perceived colour differences or changes [39,47]. Table 1 shows the colour parameters $\mathrm{L}^{*}, \mathrm{a}^{*}, \mathrm{~b}^{*}$ with mean values and standard deviations, as well as total colour differences $\left(\Delta \mathrm{E}^{*}\right)$.

Table 1. CIELab Colour Coordinates and Total Colour Differences of BCE/PU Nanofibrous Mats.

\begin{tabular}{|c|c|c|c|c|c|}
\hline Sample & Colour & $\mathbf{L}^{*}$ & $a^{*}$ & $\mathbf{b}^{*}$ & $\Delta \mathrm{E}^{*}$ \\
\hline Beginning & & $43.8 \pm 4.2$ & $22.9 \pm 1.7$ & $-1.9 \pm 0.6$ & 24.2 \\
\hline $\begin{array}{l}\text { Exposed to the } \mathrm{NH}_{3} \\
\text { Vapour }\end{array}$ & & $41.1 \pm 4.7$ & $-0.1 \pm 1.8$ & $-8.9 \pm 0.1$ & - \\
\hline After recovered & & $40.3 \pm 2.7$ & $8.9 \pm 0.1$ & $-4.4 \pm 1.0$ & 10.1 \\
\hline
\end{tabular}

The mean values and standard deviations $( \pm)$ of the three measurements were used. The sample exposed to the $\mathrm{NH}_{3}$ gas took as a reference to calculate $\Delta \mathrm{E}^{*}$ values.

The BCE/PU nanofibrous mats showed a moderate value of luminosity $\left(\mathrm{L}^{*}\right)$. The $\mathrm{a}^{*}$ colour coordinates of BCE/PU nanofibrous mats showed the highest value at the beginning and then decreased after being exposed to $\mathrm{NH}_{3}$ vapour. When exposed to ammonia, the $\mathrm{pH}$ value increased. The BCE/PU nanofibrous mats showed negative values of $\mathrm{b}^{*}$ value, representing the highest blue intensity. It was noted that 5 min after the sample was withdrawn from the gas source, $a^{*}$ positive value increased and $b^{*}$ negative value decreased, thereby indicating a purple hue. The $\Delta \mathrm{E}^{*}$ value is important for distinguishing colours at different environmental conditions. Generally, if the $\Delta \mathrm{E}^{*}$ value is greater than 5 , an observer can distinguish between two distinct colours [7,39]. As shown in Table 1, the $\Delta \mathrm{E}^{*}$ was greater than 5 , indicating good detection performance. This finding showed that the produced nanofibrous mats had a remarkable colour variance, allowing the human eye 
to see colour diversity. Similar colour changes have been seen in other black carrot-loaded nanofibrous materials [37,39]. These findings show that the BCE/PU nanofibrous mats may be used as a textile sensor for detecting $\mathrm{NH}_{3}$ gas.

In this work, a naked-eye sensor that does not require a power source or measurement equipment was developed. Therefore, it could have the potential to be used to fabricate a low-cost $\mathrm{NH}_{3}$ sensor. Additionally, it can be used to cover large surfaces, and it can still be used as a local sensor with a local colour change without having to include many separate local sensors.

\section{Conclusions}

The goal of this study was to develop a facile colourimetric nanofibrous sensor and evaluate its colour change behaviour to monitor $\mathrm{NH}_{3}$ vapour. The results revealed that colourimetric nanofibrous mats were successfully produced by electrospinning with the inclusion of BCE anthocyanin. The presence of BCE caused an irregularity in the nanofibrous mat, which was visible in the SEM images. The average size of the BCE/PU nanofibrous mats was around 250-300 nm. ATR-FTIR spectra of the electrospun mats verified the successful incorporation of BCE in nanofibres. The BCE solution showed colour shifts in the UV-visible absorbance spectra via a bathochromic shift with increasing $\mathrm{pH}$. The $\mathrm{BCE} / \mathrm{PU}$ nanofibrous had a response to $\mathrm{NH}_{3}$ vapour. The visual colour change of the sample with the medium change (ammonia vapour) was remarkable from pink-red to green-blue. The CIELab values of colourimetric nanofibrous mats showed apparent colour differences before and after exposure. This signal may aid workers who are exposed to hazardous conditions in their efforts to protect themselves from gas poisoning. According to the findings, the BCE/PU nanofibrous mat has the potential to be used as a visual indicator for monitoring $\mathrm{NH}_{3}$ vapour.

The development of simple, portable, and low-cost colourimetric sensors is a goal of this study for the rapid and in situ detection of environmental pollutants. In this regard, the BCE-loaded PU nanofibrous mat was developed for use as a colourimetric sensor in an unusual environment, and its performance was assessed. Flexible sensors, which could be useful for personal protection equipment, are currently being developed. The primary accomplishment of this study is the development of a technique for preparing colourimetric polyurethane nanofibrous sensors, which will lead to alternative materials for smart textiles. To go further, the stability of anthocyanin-loaded nanofibrous in various mediums (gas concentrations, temperatures, etc.) should be investigated. Understanding the degradation of anthocyanin-loaded nanofibrous under different conditions is critical for the development of a colourimetric sensor.

Supplementary Materials: The following are available online at https:/ / www.mdpi.com/article/10

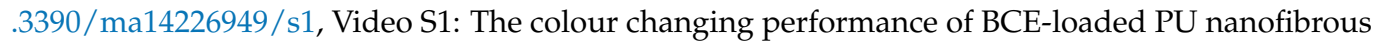
mats after exposure to ammonia vapour and subsequent removal from the vapour source.

Author Contributions: Conceptualization, A.P.; methodology, A.P.; formal analysis, A.P.; investigation, A.P.; resources, Z.D.; writing—original draft preparation, A.P.; writing—review and editing, A.P. and Z.D.; visualization, A.P.; supervision, Z.D.; funding acquisition, Z.D. All authors have read and agreed to the published version of the manuscript.

Funding: The article processing charge (APC) was funded by Lodz University of Technology. This work was supported by statutory research fund of the Institute of Material Science of Textiles and Polymer Composites no. I-42/501/4-42-1-3.

Institutional Review Board Statement: Not applicable.

Informed Consent Statement: Not applicable.

Data Availability Statement: Not applicable.

Acknowledgments: The authors would like to thank the Lodz University of Technology's Institute of Materials Science of Textiles and Polymer Composites for their assistance with the research.

Conflicts of Interest: The authors declare no conflict of interest. 


\section{References}

1. Schoolaert, E.; Hoogenboom, R.; De Clerck, K. Colorimetric nanofibers as optical sensors. Adv. Funct. Mater. 2017, $27,1702646$. [CrossRef]

2. Van der Schueren, L.; De Clerck, K. Coloration and application of pH-sensitive dyes on textile materials. Color. Technol. 2012, 128, 82-90. [CrossRef]

3. Allied Analytics LLP, Sensor Market Outlook 2028. Available online: https://www.alliedmarketresearch.com/sensor-market (accessed on 19 August 2021).

4. Alberti, G.; Zanoni, C.; Magnaghi, L.R.; Biesuz, R. Disposable and Low-Cost Colorimetric Sensors for Environmental Analysis. Int. J. Environ. Res. Public Health 2020, 17, 8331. [CrossRef] [PubMed]

5. Sholihah, W.; Listyarini, A.; Fitriana, R.; Imawan, C. A paper-based visual indicator for detection of ammonia using Ruellia simplex. IOP Conf. Ser. Mater. Sci. Eng. 2019, 496, 012050. [CrossRef]

6. Listyarini, A.; Fauzia, V.; Imawan, C. A simple paper-based color change label using plant extracts for Ammonia gas detection. J. Phys. Conf. Ser. 2020, 1528, 012056. [CrossRef]

7. Park, Y.K.; Oh, H.J.; Bae, J.H.; Lim, J.Y.; Lee, H.D.; Hong, S.I.; Son, H.S.; Kim, J.H.; Lim, S.J.; Lee, W. Colorimetric Textile Sensor for the Simultaneous Detection of $\mathrm{NH}_{3}$ and $\mathrm{HCl}$ Gases. Polymers 2020, 12, 2595. [CrossRef]

8. Park, Y.K.; Oh, B.M.; Jo, A.R.; Han, J.H.; Lim, J.Y.; Oh, H.J.; Lim, S.J.; Kim, J.H.; Lee, W.S. Fabrication of colorimetric textile sensor based on rhodamine dye for acidic gas detection. Polymers 2020, 12, 431. [CrossRef] [PubMed]

9. Oh, H.J.; Yeang, B.J.; Park, Y.K.; Choi, H.J.; Kim, J.H.; Kang, Y.S.; Bae, Y.; Kim, J.Y.; Lim, S.J.; Lee, W.; et al. Washable Colorimetric Nanofiber Nonwoven for Ammonia Gas Detection. Polymers 2020, 12, 1585. [CrossRef]

10. Rostami, S.G.; Bafqi, M.S.S.; Bagherzadeh, R.; Latifi, M.; Gorji, M. Multi-layer electrospun nanofiber mats with chemical agent sensor function. J. Ind. Text. 2015, 45, 467-480. [CrossRef]

11. Ramakrishna, S.; Fujihara, K.; Teo, W.; Lim, T.; Ma, Z. An Introduction to Electrospinning and Nanofibers; World Scientific Publishing, Co.: Singapore, 2005.

12. Li, Y.; Abedalwafa, M.A.; Tang, L.; Li, D.; Wang, L. Chapter 18-Electrospun Nanofibers for Sensors. In Micro and Nano Technologies, Electrospinning: Nanofabrication and Applications, 1st ed.; Ding, B., Wang, X., Yu, J., Eds.; William Andrew: Amsterdam, The Netherlands, 2019; pp. 571-601.

13. Huang, C.; Thomas, N.L. Fabrication of porous fibers via electrospinning: Strategies and applications. Polym. Rev. 2020, 60, 595-647. [CrossRef]

14. Pakolpakç1l, A.; Draczynski, Z. Green approach to develop bee pollen-loaded alginate based nanofibrous mat. Materials 2021, 14, 2775. [CrossRef]

15. Pakolpakçıl, A.; Draczynski, Z. Preparation and characterization of the advanced alginate-based nanofibrous nonwoven using EDC/NHS coupling agent by electrospinning. J. Text. Inst. 2021, 1-9. [CrossRef]

16. Gu, Y.; Huang, J. Colorimetric detection of gaseous ammonia by polyaniline nanocoating of natural cellulose substances. Colloids Surf. A Physicochem. Eng. Asp. 2013, 433, 166-172. [CrossRef]

17. Owyeung, R.E.; Panzer, M.J.; Sonkusale, S.R. Colorimetric gas sensing washable threads for smart textiles. Sci. Rep. 2019, 9, 560. [CrossRef]

18. Ly, A.; Luo, Y.; Cavaillès, G.; Olivier, M.-G.; Debliquy, M.; Lahem, D. Ammonia sensor based on vapor phase polymerized polypyrrole. Chemosensors 2020, 8, 38. [CrossRef]

19. Lee, J.; Kim, T. Synthesis of novel coumarin-based acid vapochromic fluorescence dye showing change of both color and fluorescence emission spectrum for application to sensitive, reusable, and washable textile sensors. Text. Res. J. 2021, 91, 5-6. [CrossRef]

20. Lee, J.; Jun, H.; Kubota, Y.; Kim, T. Synthesis of red fluorescent dye with acid gas sensitive optical properties and fabrication of a washable and wearable textile sensor. Text. Res. J. 2021, 91, 17-18. [CrossRef]

21. Hong, T.; Choi, Y.; Lim, K.T.; Seo, K.; Jeong, S.M.; Ju, S. Elastic halochromic fiber as a reversible pH sensor. Adv. Mater. Technol. 2021, 6, 1-10. [CrossRef]

22. Atav, R.; Akkuş, E.; Ergünay, U. Investigation of the Dyeability of Cotton Fabrics with a Halochromic Dye According to Exhaust and Padding Methods. J. Nat. Fibers 2021, 1-14. [CrossRef]

23. Haq, S.U.; Aghajamali, M.; Hassanzade, H. Cost-effective and sensitive anthocyanin-based paper sensors for rapid ammonia detection in aqueous solutions. RSC Adv. 2021, 11, 24387-24397. [CrossRef]

24. Nafady, A.; Al-Enizi, A.M.; Alothman, A.A.; Shaikh, S.F. Design and fabrication of green and sustainable vapochromic cellulose fibers embedded with natural anthocyanin for detection of toxic ammonia. Talanta 2021, 230, 122292. [CrossRef] [PubMed]

25. Manesh, K.M.; Gopalan, A.I.; Lee, K.; Santhosh, P.; Song, K.; Lee, D. Fabrication of Functional Nanofibrous Ammonia Sensor. IEEE Trans. Nanotechnol. 2007, 6, 513-518. [CrossRef]

26. Pang, Z.; Yang, Z.; Chen, Y.; Zhang, J.; Wang, Q.; Huang, F.; Wei, Q. A room temperature ammonia gas sensor based on cellulose/TiO2/PANI composite nanofibers. Colloids Surf. A Physicochem. Eng. Asp. 2016, 494, 248-255. [CrossRef]

27. Hoang, A.T.; Cho, Y.B.; Park, J.S.; Yang, Y.; Kim, Y.S. Sensitive naked-eye detection of gaseous ammonia based on dye-impregnated nanoporous polyacrylonitrile mats. Sens. Actuators B 2016, 230, 250-259. [CrossRef] 
28. Geltmeyer, J.; Vancoillie, G.; Steyaert, I.; Breyne, B.; Cousins, G.; Lava, K.; Hoogenboom, R.; De Buysser, K.; De Clerck, K. Dye modification of nanofibrous silicon oxide membranes for colorimetric $\mathrm{HCl}$ and $\mathrm{NH}_{3}$ sensing. Adv. Funct. Mater. 2016, 26, 5987-5996. [CrossRef]

29. Kim, D.H.; Cha, J.H.; Lim, J.Y.; Bae, J.; Lee, W.; Yoon, K.R.; Kim, C.; Jang, J.S.; Hwang, W.; Kim, D. Colorimetric Dye-Loaded Nanofiber Yarn: Eye-Readable and Weavable Gas Sensing Platform. ACS Nano 2020, 14, 16907-16918. [CrossRef]

30. Schoolaert, E.; Merckx, R.; Becelaere, J.; Rijssegem, S.; Hoogenboom, R.; De Clerck, K. Eco-Friendly Colorimetric Nanofiber Design: Halochromic Sensors with Tunable pH-Sensing Regime Based on 2-Ethyl-2-Oxazoline and 2-n-Butyl-2-Oxazoline Statistical Copolymers Functionalized with Alizarin Yellow R. Adv. Funct. Mater. 2021, 2106859. [CrossRef]

31. Khoo, H.E.; Azlan, A.; Tang, S.T.; Lim, S.M. Anthocyanidins and anthocyanins: Colored pigments as food, pharmaceutical ingredients, and the potential health benefits. Food Nutr. Res. 2017, 61, 1361779. [CrossRef] [PubMed]

32. Rakić, V.; Ulrih, N.P. Influence of $\mathrm{pH}$ on color variation and stability of cyanidin and cyanidin 3-O- $\beta$-glucopyranoside in aqueous solution. CyTA-J. Food 2021, 19, 174-182. [CrossRef]

33. Saleem, M.Q.; Akhtar, S.; Imran, M.; Riaz, M.; Rauf, A.; Mubarak, M.S.; Bawazeer, S.; Bawazeer, S.S.; Hassanien, M.F. Antibacterial and anticancer characteristics of black carrot (Daucus Carota) extracts. J. Med. Spice Plants 2018, 22, 40-44.

34. Montilla, E.C.; Arzaba, M.R.; Hillebrand, S.; Winterhalter, P. Anthocyanin composition of black carrot (daucus carota ssp. sativus var. atrorubens alef.) cultivars antonina, beta sweet, deep purple, and purple haze. J. Agric. Food Chem. 2011, 59, 3385-3390. [CrossRef] [PubMed]

35. Espinosa-Acosta, G.; Ramos-Jacques, A.L.; Molina, G.A.; Maya-Cornejo, J.; Esparza, R.; Hernandez-Martinez, A.R.; SánchezGonzález, I.; Estevez, M. Stability Analysis of Anthocyanins Using Alcoholic Extracts from Black Carrot (Daucus Carota ssp. Sativus Var. Atrorubens Alef.). Molecules 2018, 23, 2744.

36. Goksen, G.; Ekiz, H.I. Electrospun poly (vinyl alcohol) with anthocyanins from black carrot nanofibrous film for $\mathrm{pH}$ biosensor applications. J. Biotechnol. 2018, 280, S26. [CrossRef]

37. Moradi, M.; Tajik, H.; Almasi, H.; Forough, M.; Ezati, P. A novel pH-sensing indicator based on bacterial cellulose nanofibers and black carrot anthocyanins for monitoring fish freshness. Carbohydr. Polym. 2019, 222, 115030. [CrossRef] [PubMed]

38. Goodarzi, M.M.; Moradi, M.; Tajik, H.; Forough, M.; Ezati, P.; Kuswandi, B. Development of an easy-to-use colorimetric pH label with starch and carrot anthocyanins for milk shelf life assessment. Int. J. Biol. Macromol. 2020, 153, 15.

39. Pakolpakçıl, A.; Osman, B.; Özer, E.T.; Şahan, Y.; Becerir, B.; Göktalay, G.; Karaca, E. Halochromic composite nanofibrous mat for wound healing monitoring. Mater. Res. Express 2019, 6, 1250c3. [CrossRef]

40. Basf, Elastollan ${ }^{\circledR T e c h n i c a l ~ D a t a ~ S h e e t . ~ A v a i l a b l e ~ o n l i n e: ~ h t t p: / ~ / w w w . e l a s t o l l a n . b a s f . u s / p d f / 1185 A W . p d f ~(a c c e s s e d ~ o n ~} 1$ March 2021).

41. Akduman, C.; Kumbasar, E.P.A. Electrospun polyurethane nanofibers. In Aspects of Polyurethanes; Yilmaz, F., Ed.; IntechOpen: Rijeka, Croatia, 2017.

42. Mohraz, M.H.; Golbabaei, F.; Yu, I.J.; Mansournia, M.A.; Zadeh, A.S.; Dehghan, S.F. Preparation and optimization of multifunctional electrospun polyurethane/chitosan nanofibers for air pollution control applications. Int. J. Environ. Sci. Technol. 2019, 16, 681-694. [CrossRef]

43. Mistry, P.; Chhabra, R.; Muke, S.; Narvekar, A.; Sathaye, S.; Jain, R.; Dandekar, P. Fabrication and characterization of starch-TPU based nanofibers for wound healing applications. Mat. Sci. Eng. C 2021, 119, 111316. [CrossRef]

44. Kim, Y.N.; Ha, Y.M.; Park, J.E.; Kim, Y.O.; Jo, J.Y.; Han, H.; Lee, D.C.; Kim, J.; Jung, Y.C. Flame retardant, antimicrobial, and mechanical properties of multifunctional polyurethane nanofibers containing tannic acid-coated reduced graphene oxide. Polym. Test. 2021, 93, 107006. [CrossRef]

45. Mrunalini, K.G.; Pudke, S.P.; Sharma, C.S. Neem oil encapsulated electrospun polyurethane nanofibrous bags for seed storage: A step toward sustainable agriculture. J. Appl. Polym. Sci. 2021, 138, 11.

46. Wang, Y.; Li, W.; Zhou, Y.; Jiang, L.; Ma, J.; Chen, S.; Jerrams, S.; Zhou, F. Fabrication of high-performance wearable strain sensors by using CNTs-coated electrospun polyurethane nanofibers. J. Mater. Sci. 2020, 55, 12592-12606. [CrossRef]

47. Fdhal, N.; Kyan, M.; Androutsos, D.; Sharma, A. Color Space Transformation from RGB to CIELAB Using Neural Networks. In Advances in Multimedia Information Processing-PCM 2009 Lecture Notes in Computer Science, 5879; Muneesawang, P., Wu, F., Kumazawa, I., Roeksabutr, A., Liao, M., Tang, X., Eds.; Springer: Heidelberg/Berlin, Germany, 2009.

48. Nirmala, R.; Nam, K.T.; Navamathavan, R.; Park, S.J.; Kim, H.Y. Hydroxyapatite mineralization on the calcium chloride blended polyurethane nanofiber via biomimetic method. Nanoscale Res. Lett. 2011, 6, 2. [CrossRef] [PubMed]

49. Agarwal, A.; Raheja, A.; Natarajan, T.S.; Chandra, T.S. Development of Universal pH Sensing Electrospun Nanofibers. Sens. Actuators B 2012, 161, 1097-1101. [CrossRef]

50. Pakolpakçll, A.; Karaca, E.; Becerir, B. Investigation of a natural pH-indicator dye for nanofibrous wound dressings. IOP Conf. Ser. Mater. Sci. Eng. 2018, 460, 012020. [CrossRef]

51. Koosha, M.; Hamedi, S. Intelligent Chitosan/PVA nanocomposite films containing black carrot anthocyanin and bentonite nanoclays with improved mechanical, thermal and antibacterial properties. Prog. Org. Coat. 2019, 127, 338-347. [CrossRef]

52. Zeb, A. Phenolic Antioxidants in Foods: Chemistry, Biochemistry and Analysis; Springer International Publishing: Heidelberg, Germany, 2021.

53. Castañeda-Ovando, A.; Pacheco-Hernández, M.D.L.; Páez-Hernández, M.E.; Rodríguez, J.A.; Galán-Vidal, C.A. Chemical studies of anthocyanins: A review. Food Chem. 2009, 113, 859-871. [CrossRef] 
54. Tang, B.; He, Y.; Liu, J.; Zhang, J.; Li, J.; Zhou, J.; Ye, Y.; Wang, J.; Wang, X. Kinetic investigation into pH-dependent color of anthocyanin and its sensing performance. Dyes Pigm. 2019, 170, 107643. [CrossRef]

55. Pakolpakçıl, A.; Osman, B.; Göktalay, G.; Özer, E.T.; Şahan, Y.; Becerir, B.; Karaca, E. Design and in vivo evaluation of alginate based $\mathrm{pH}$-sensing electrospun wound dressing containing anthocyanins. J. Polym. Res. 2021, 28, 50. [CrossRef] 